\title{
Urban agriculture is a gateway to healthy foods
}

A s we often boast, California is home to 81,000 farms and ranches that produce more than 400 different varieties of fruits, vegetables, nuts and other products, making "California grown" synonymous with the best-grown commodities in the nation. Farming occurs in some form in each of the state's 58 counties, but each day too many Californians go without access to fresh and healthy food. Many of these people, living in both rural and urban communities scattered around the state, suffer from poor health and diet-related illnesses and experience an overall lower quality of life because they do not have access to affordable healthy foods.

For more than 50 years, California has led the nation in agricultural production, yet nearly 1 million of our residents live in areas known as "food deserts." Found mostly in urban settings, these areas do not provide affordable, fresh and nutritious fruits, vegetables and dairy products. As a result, those living in food deserts suffer from higher rates of obesity, diabetes, heart disease and cancer, and they experience higher instances of premature death. These ailments and premature deaths can be reduced with access to

\section{Research from} the University of California shows that small-level farming in cities is not an unreasonable enterprise.

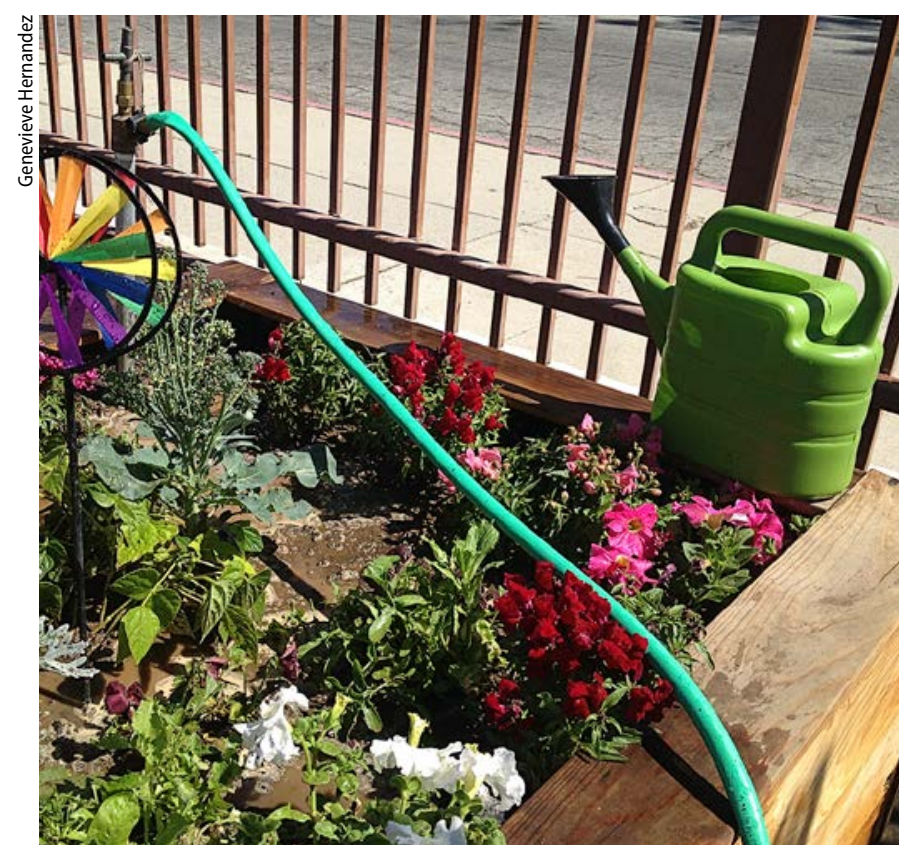

number of farmers markets increased from 580 to 729 locations statewide, sparked by a desire from urban residents to have greater access to healthy produce.

I have firsthand knowledge of the economic benefits that occur in communities that combat food deserts. I worked for nearly a decade to bring a full-service grocery store to the Downtown Los Angeles neighborhood I now represent. The community-which was previously considered a food desert-is now home to one of the most profitable stores in the entire chain. Bringing that grocery store to this neighborhood not only improved public health but also benefitted the local economy.

Every Californian has the right to healthy and affordable food. That's why I created the California Healthy Food Financing Initiative in 2011, which will work to increase access to healthy food items in underserved urban and rural communities. I furthered this action in 2012 with my legislation AB 2246, which helps facilitate financing to support projects that increase access to healthy foods.

Planting community gardens in vacant lots, growing vegetables in backyards and on rooftops, and increasing the number of farmers markets are just some of the activities that will improve the quality of life for residents in underserved urban areas. Research from the University of California shows that small-level farming in cities is not an unreasonable enterprise, and more people are realizing this. Working with UC Cooperative Extension, UCLA researchers identified almost 1,300 urban agriculture sites in Los Angeles County's 88 cities and unincorporated areas.

There are many creative ways Californians can help their neighborhoods-whether it's lobbying to site a grocery store with fresh produce near

their homes, creating a mobile food bank to reach those in the community without transportation or estab-

\section{Every Californian has the right to healthy and affordable food.}

lishing a community

garden today so that people can eat healthy tomorrow.

Urban agriculture has multiple benefits because when communities eat healthier, children can focus better in school, workers can be more productive and the people living in the area can lower their rates of obesity-related ailments, which in turn, decreases medical bills and helps families save money. By providing better access to healthy foods, communities plant the seeds for a better California.

Assembly Speaker John A. Pérez (D-Los Angeles) represents urban neighborhoods such as Boyle Heights, Downtown Los Angeles and Westlake. 